\title{
Intervenções farmacêutica: práticas que fazem a diferença
}

\author{
Pharmaceutical interventions: practices that make a difference \\ Intervenciones farmacéuticas: prácticas que marcan la diferencia
}

Luiz Henrique Gomes dos Santos ORCID: https://orcid.org/0000-0002-0854-9511

Universidade Salvador, Brasil

E-mail: Henrique.farma93@gmail.com

\begin{abstract}
Resumo
Ao se investigar sobre tal problema, o objetivo é de perceber ele ocorre, absorvendo-o de forma crítica e perceptível ao entendimento teórico científico. $\mathrm{O}$ trabalho é importante para se entender a configuração concreta desse problema e a sua observação no meio profissional, social e técnico no qual se apresentam suas categorias. O objetivo é identificar intervenções farmacêuticas como práticas que fazem a diferença. demasiadamente relevante para a formação compreender como ocorre. Portanto, busca-se elucidar perguntas que se fazem nesse aspecto. Justifica-se a criação de textos que possam mostrar como ocorre, e sua importância diante dos estudos de formação profissional, além de possibilitar maiores discussões sobre conceitos, categorias e os aspectos de aplicação ao campo de sua intervenção. Assim, através de uma breve revisão da literatura, estuda-se sobre tal temática, incutindo-a aos pensamentos do contexto contemporâneo que a atualizam em respostas às nossas maiores curiosidades sobre tal ocorrência.
\end{abstract}

Palavras-chave: Administração farmacêutica; Farmácia; Intervenções.

\begin{abstract}
When investigating such a problem, the objective is to notice it occurs, absorbing it in a critical and perceptible way to the scientific theoretical understanding. The work is important to understand the concrete configuration of this problem and its observation in the professional, social and technical environment in which its categories are presented. The objective is to identify pharmaceutical interventions as practices that make a difference. too relevant for training to understand how it happens. Therefore, it seeks to elucidate questions that are asked in this aspect. It justifies the creation of texts that can show how it happens, and its importance in the face of studies on professional training, in addition to enabling further discussions on concepts, categories and aspects of application to the field of intervention. Thus, through a brief literature review, this theme is studied, instilling it in the thoughts of the contemporary context that update it in response to our greatest curiosities about such an occurrence.
\end{abstract}

Keywords: Interventions; Pharmacy; Pharmacy administration.

\section{Resumen}

Al investigar tal problema, el objetivo es darse cuenta de que ocurre, absorbiéndolo de manera crítica y perceptible para el entendimiento científico teórico. El trabajo es importante para comprender la configuración concreta de esta problemática y su observación en el entorno profesional, social y técnico en el que se presentan sus categorías. El objetivo es identificar las intervenciones farmacéuticas como prácticas que marcan la diferencia. demasiado relevante para que la formación entienda cómo sucede. Por tanto, busca dilucidar las cuestiones que se plantean en este aspecto. Justifica la creación de textos que puedan mostrar cómo ocurre, y su importancia de cara a los estudios sobre formación profesional, además de posibilitar mayores discusiones sobre conceptos, categorías y aspectos de aplicación al campo de intervención. Así, a través de una breve revisión de la literatura, se estudia este tema, inculcándolo en el pensamiento del contexto contemporáneo que lo actualiza en respuesta a nuestras mayores curiosidades sobre tal hecho.

Palabras clave: Administración farmacêutica; Farmácia; Intervenciones.

\section{Introdução}

Destacando o contexto que se refere a tal assunto, este artigo serve como fonte de atualização dos conhecimentos sobre este tema em dados qualitativos, enquanto exigências a novos conhecimentos. Além disso, é devida a oportunidade de esclarecimentos por parte de vários autores adiante invocados na compreensão deste fenômeno. 
O objetivo é investigar e emitir considerações sobre tal fenômeno, e para atingi-lo, faz-se necessário perceber conceitos, indicar suas utilizações e mostrar como se coloca diante da projeção que é feita com o problema de pesquisa. Que, neste caso foi: como as intervenções farmacêuticas se tornam práticas que fazem a diferença?

Em resposta, observa-se que esta ocorrência é de fato compreendida dentro da visão científica, que se incrementa com a amplitude da sociedade em questão, conduzindo-se a uma leitura pautada da realidade imposta por meio desse apontamento.

A justificativa é de que haja importância na edificação de estudos que versem sobre essa temática como fonte de novos conhecimentos, pois se rebuscam conteúdos que podem interagir com nossas mais amplas curiosidades a seu respeito e com alto grau de teor informativo.

No campo prático, um trabalho nessa dimensão é altamente informativo e capaz de contribuir em muitos sentidos. Portanto, ele pode possibilitar como uma fonte de guia orientativo a profissionais que buscam se atualizar com os conceitos dessa praticidade trabalhados ao longo desta breve discussão técnica.

Da mesma forma, sua relevância prática é observada em poder nortear atividades construtivas ao percurso profissional, estabelecendo com as operacionalidades um corpo homogêneo de conteúdos com a finalidade de basear atendimentos neste sentido.

Aplica-se para resposta, uma breve revisão de literatura, mais bem informada no tópico de referencial teórico, que indica a apropriação de materiais e métodos necessários na construção desse corpo teórico investigativo.

\section{Metodologia}

A natureza bibliográfica da pesquisa foi adotada na busca por resultados. Entende-se que nesse caso, as abordagens qualitativas de pesquisa se fundamentam numa perspectiva que concebe o conhecimento como um processo socialmente construído pelos sujeitos nas suas interações cotidianas, enquanto atuam na realidade transformando-a e sendo por ela transformada (Marconi \& Lakatus, 2014).

Ponderando que, no fato de a pesquisa qualitativa ser caracterizada por um espectro de métodos e técnicas adaptados ao caso específico, ao invés de um método padronizado único, ressalta-se assim, que o método deve se adequar ao objeto de estudo, isto conforme Minayo (2017).

A pesquisa ocorreu entre o segundo e terceiro trimestre de 2021, com a escolha do tema, dos objetivos, da justificativa e das discussões que seriam realizadas nessa empreitada. Foram inicialmente realizadas leituras focalizadas em autores que indicassem pertinência ao problema dessa pesquisa.

Nessa busca, adentrou-se às bases Google Scholar, Scielo.BR; e Plataforma Capes pelos termos "intervenções" AND “Administração farmacêutica" AND "farmácia” escolhendo entre os achados, títulos pertinentes a nosso problema, sem levar em consideração filtros como ano de publicação ou idioma, devido à grandiosidade desta temática, autores clássicos foram bem-vindos.

Ao final, escrevendo as considerações, tomou-se por base os melhores pensamentos que foram coletados dos autores pesquisados, movendo com eles uma releitura compactada e apropriada de senso crítico respeitoso da realidade na qual esse fenômeno ocorre.

\section{Resultados e Discussão}

\subsection{Práticas Farmacêuticas: Conceitos}

Todos os processos previstos na legislação irão poder ser redigidos no estereótipo de Manual de Excelentes Práticas acurado ao sentido de aceitação social, que carece ser redigido e acatados pelo Farmacêutico Responsável Técnico (RT) (Oliveira et al., 2019). 
O RT deve padronizar os Procedimentos Operacionais Padrão (POP), descrevendo as rotinas da unidade das corporações e inserindo todas essas fases seguintes como os profissionais envolvidos na sua execução (Trindade et al., 2019).

Os POPs irão poder ser acatados, assinados e datados pelo RT. Devem estar previstas mudanças periódicas do Manual e além disso, POPs, tal como formas de treino com respeito ao conteúdo aos trabalhadores envolvidos com as atividades exercidas acertadamente (Matias \& Miranda, 2018).

Certamente, Excelentes Práticas de Fabricação (BPF) asseguram que os remédios possam ser consistentemente feitos e controlados conforme quesitos mínimos de qualidade previamente determinados. Têm por objetivo chefiar e diminuir os riscos inerentes à fabricação de remédios com vista a promoter nível de exigência da operacionalidade e segurança do excelente produto acabado (Gramosa et al., 2018).

Desde seu aparecimento da forma com a qual é sabido atualmente outras muitas versões se sucederam no território brasileiro e no planeta. Este trabalho se propõe a estudar as BPF, através da argumentação de conteúdo dos marcos regulatórios brasileiros, identificando os novos acontecimentos com respeito aos que se determinam que conseguem demonstrar sua evolução por meio das últimas décadas.

Certamente, BPF tinham sido decompostas em assuntos e subtemas e suas versões, em atividades nos 5, marcos regulatórios fielmente analisados, tinham sido estudadas cuidadosamente. tivera sido realizável auferir, na evolução dos quesitos de fabricação de remédios, a obstrução das atualizações tecnológica e igualmente a influência de atuais experiências direcionadas à qualidade, identificando, de tal forma, a operacionalidade (em sua dinâmica) de transformação das BPF (Trindade et al., 2019, Matias \& Miranda, 2018).

Certamente, Excelentes Práticas de Fabricação (BPF) são o aparato instrumental que ajustou e técnico que confirma que os remédios possam ser consistentemente feitos e controlados conforme quesitos mínimos de qualidade previamente determinados. Têm como objetividade o controle gerencial e igualmente a minimização dos riscos envolvidos na fabricação de remédios, com vista a promoter nível de exigência da operacionalidade e segurança do excelente produto acabado (Oliveira et al., 2019).

Certamente, boas práticas de farmácia aparecem enquanto iniciativa da Organização Mundial da Saúde (OMS) em 1967, com o objetivo de apoiar os empenhos despendidos por meio de seus estados-membros para engrandecer o nível de condição da dos remédios comercializados (Trindade et al., 2019).

Os documentos acatados na 21 Assembleia Mundial de Saúde, intitulado Draft requirements for good manufacturing practices in the manufacture and quality control of drugs and pharmaceutical specialities, constitui o primeiro texto oficial que identifica no das normas de fabricação de remédios usando o termo BPF. Desde aqui, outras muitas mudanças de tal documento tinha sido produzidas à OMS durante as décadas seguintes, sendo percebida a última delas em 2014 (Azize, 2017).

A evolução das normas de fabricação de remédios está usualmente vinculada a desastres de grande repercussão midiática, abarcando o consumo de remédios sem qualidade que chamaram consigo que ofereçam certos acontecimentos prejuízos ao bem-estar físico dos atendidos, e em exemplos, conduziram a óbito dezenas de doentes.

De forma ilustrativa, são apresentados os incidentes abarcando o remédio sufatiazol, em 1941 nos EUA (EUA), que abandonou em torno de 300 mortos ou feridos por causa da ingestão de drágeas contaminado por fenobarbital e, depois disso, ainda, o fato da falha sob o desenvolvimento da inativação viral de lote de vacina da pólio nos anos 1950, que possibilitou que 60 indivíduos desenvolvessem pólio e diferentes 89 familiares contraíssem a enfermidade, nos EUA (Azize, 2017).

Ainda atualmente sinistros fatais por causa da ausência de qualidade dos remédios acabam ficando a ocorrer ao redor do mundo, inclusive no Brasil ${ }^{4}$. Em resposta a cada uma dessas tragédias podem-se se identificar outras muitas ações governamentais subsequentes ${ }^{5}$, tomadas através dessas autoridades sanitárias de distintas unidades de saúde dos Estados, no intuito de adotar medidas restritivas direcionadas à fabricação de medicamentos (Rocha \& Giotto, 2020). 
Segundo Oliveira et al, (2019), Gramosa et al., (2018), Rocha e Giotto (2020) conectam o desenvolvimento da sua observação com relação a um definido objeto, como é o fato das BPF, ao aperfeiçoamento tecnológico.

Já com respeito a indicações de iatrogenias decorrentes dos atuais conhecimentos técnicos, defende que o aperfeiçoamento tecnológico impõe uma observação cada vez maior à mesma porção de risco, que o uso de conhecimentos técnicos mais bastante desenvolvidas torna-se hábil de fazer resultados preferíveis, mas cobra que embora seja praticado, sob estritos controles e critérios para as boas práticas de farmácia (Gramosa et al., 2018).

Por isto, conhecimentos mais técnicos de momento demandam maior vigilância às boas práticas farmacêuticas, para ela se faz preciso ter maior conhecimento dos meios humanos, mais expertise, maior capacidade individual e experiência (Oliveira et al., 2019).

Outrossim, se transforma importante balizar o significado como também o consumo do termo tecnologia. no meio dos diferentes significados e interpelações aplicáveis a este termo, que mais se chega próximo a à realidade da fabricação de remédios é observada enquanto a criação de Blaumer, que diz respeito ao conjunto de objetos físicos e operações operacionalidades (mecanizadas ou manuais) empregadas na transformação de utensílios/produtos em uma indústria. Baseando-se nisso, Silva propôs uma nova interpelação do termo na área da administração da tecnologia em corporações de manufatura (Rocha \& Giotto, 2020).

O autor Rocha e Giotto (2020) trabalhou os significados de macrotecnologia, indicado ao conceito sistêmico em meio a organização (estrutura, imaginação, comunitários, informação, organização etc.),

Adiante, a indicação de remédios como a microtecnologia, referente ao conjunto de conhecimentos técnicos interrelacionadas embutidas num processo ou produto é feito por farmacêutico (Matias \& Miranda, 2018). Ao indicar a microtecnologia, revela-se, de tal forma, em Tecnologias Complementares (TC), contempladas num processo ou excelente produto, que por sua vez, é chamado de Tecnologia Principal (TP).

Em conformidade com essa interpelação, as TC se decorrem de um modo mais intensa e arrebatadora e acelerada que as TP. Para o autor, a maior parte das adequações em utensílios/produtos acontece em consequência do avanço das TC e não das TP.

A caracterização dos conhecimentos técnicos empregadas nas fábricas farmacêutica torna-se hábil de tornar ainda mais fácil o significado da operacionalidade (em sua dinâmica) de evolução das BPF durante das últimas décadas (Gramosa et al., 2018, Azize, 2017).

Os estudos científicos colocados em observação nas BPF de remédios e sua relação com as atualizações tecnológicas, tal como diferentes aceitáveis fatos sobre os quais se determinam, são escassos.

Nesse contexto, este trabalho se propõe a sondar o desenvolvimento da transformação das BPF como também suas motivações, que será adotado como sentido de análise o Brasil. A evolução da ajustagem sanitária do país em BPF como também as recomendações estrangeiras que funcionaram como bases tinham sido analisadas de um modo sistematizada, identificando as características científicos envolvidos e no seu impacto nas BPF.

\subsection{A importância das práticas farmaceuticas}

A importância da ação do profissional de farmácia está bastante perpassando o mero assistente que pega uma receita e irá buscar o remédio atrás do balcão. Existe um conceito chamado Atenção Farmacêutica, que tem como base a expertise trabalhista na qual o enfermo é o mais importante dependente das ações do profissional de farmácia.

De acordo com a Organização Mundial da Saúde (OMS), a farmácia é o compêndio das ações próprias de promoção em saúde, dos comportamentos, dos compromissos, das inquietudes, dos valores éticos, das atribuições, dos conhecimentos, 
das obrigações e das qualificações do profissional de farmácia na excelente prestação da farmacoterapia, com a objetividade de adquirir resultados terapêuticos aprovados na saúde e sob a qualidade de vida do paciente (Corrêa \& Leite, 2008).

O termo, nascido na língua inglesa, Pharmaceutical Care, surgiu em 1990, enquanto conceituação em uma nova análise da filosofia de prática farmacêutica (Trindade et al., 2019).

Nas boas práticas, o profissional farmacêutico tem diante disso a atribuição de conduzir o cliente/paciente da forma mais correta de fazer uso do medicamento, embora seja para qual tratamento, sua dosagem, frequências, armazenamentos, efeitos em outras frações do organismo, relações de interatividades com demais fármacos e etc, isto é, a correta forma de fazer uso o material componente ou matéria prima.

Às vezes, pequenos espaços de tempo conversam o potencial de como o profissional de farmácia torna-se hábil de acabar apontando um tratamento mais competente - afinal, a resolução n ${ }^{\circ}$ 586/2003 da Agência Nacional de Vigilância Sanitária (Anvisa) esclarece que o mesmo se torna hábil de prescrever remédios que não exijam prescrição médica. Essa relação de interatividade direta com o profissional de farmácia esclarece, indagações e busca trazer mais segurança ao paciente (Trindade et al., 2019).

Vale não confundir com outro termo idêntica, e até parceiro em ações que beneficiam o enfermo, o da Assistência Farmacêutica: segundo a resolução no 338 de 6 de maio de 2004, do Conselho Nacional de Saúde, é o conjunto de ações que incentivam protegem e reestabelecem a saúde, tanto individual quanto coletiva, qual o remédio é o material, componente ou matéria parente indispensável.

Simultaneamente, há ações voltadas ao acesso ao remédio e na sua utilização lógica. Nessa assimilação, envolve-se a investigação, o desenvolvimento e produção de fármacos. Além do mais, a própria escolha, a dispensação e demais processos posteriores à otimização do seu uso são otimizados.

\subsection{Práticas farmaceuticas que fazem a diferença}

\subsubsection{Rastreamento em saúde}

Faz-se a atividade da farmácia clínica inclinada a indivíduos assintomáticas, com objetivo de descobrir e se identificar riscos e mutações de saúde que conseguem ser simplesmente relatadas a uma enfermidade (Mendonça \& Leite, 2008).

Um exemplo é observado enquanto a análise da glicemia capilar e do risco de diabetes, que se tornam hábeis de identificar um doente com Diabetes mellitus que não conhecia que tinha a enfermidade. Nessa assimilação, o profissional de farmácia torna-se hábil de encaminhá-lo ao profissional de medicina, caso necessário (Farina \& Romano, 2009).

Nos EUA, por exemplo, as redes de farmácias investem nas maiores feiras de saúde, afuniladas na sugestão de testes de saúde e detecção acelerada de doenças. No Brasil, caso houvesse tal cultura, poderíamos ter maior tráfego nas farmácias, incentivando gradualmente a comercialização de utensílios/produtos e serviços de saúde (Matias \& Miranda, 2018).

\subsubsection{Consulta farmacêutica}

O doente busca trazer uma lamenta, referências e sintomas que iriam poder ser tratados numa farmácia. Nessa assimilação, o profissional de farmácia torna-se hábil de, nesses exemplos, recomendar e prescrever fármacos que não cobram receita médica, tal como medidas não farmacológicas e dar encaminhamento ao enfermo para depois procurar a medicina, nos casos de urgência ((Matias \& Miranda, 2018). 


\subsubsection{Conciliação de medicamentos}

A farmacoterapia possui uma natureza multiprofissional, pois envolve vários profissionais de maneira direta ou indireta no cuidado ao paciente. Desta forma, todos eles devem observar com o objetivo de minimizar falhas no processo farmacológico, visando certificar a segurança e as boas práticas assistenciais (Santos et al. 2019).

A atuação clínica do farmacêutico nesse processo junto à equipe multidisciplinar tem como objetivo promover uma terapia medicamentosa de qualidade para o paciente, uma vez que cabe ao farmacêutico orientar os profissionais a importância do uso seguro e racional dos medicamentos (Ribeiro et al. 2015).

O profissional farmacêutico conhece de perto de 1 a cada 5 pacientes habituais, entre eles geralmente os idosos, que muitas vezes são re-hospitalizados nos trinta dias depois da alta, sendo cerca de 50\% de tais internamentos evitáveis, e $66 \%$ são associados a problemas com os medicamentos. Este serviço da Farmácia Clínica é pensado para enfermos que guardaram altíssima hospitalar recente (Godeiro, 2008).

Considera-se que, muitas vezes os enfermos se confundem com prescrições de diferentes profissionais de medicina distintas e não se conhece o que medicamento deve continuar a tomar adiante sai do ambiente hospitalar.

Portanto, conciliar corresponde a fazer uma melhor checagem de todas essas prescrições e descobrir como se identificar discrepâncias que necessitam ser decididas, e conduzir o enfermo com respeito à forma mais correta de tomar os medicamentos (Matias \& Miranda, 2018).

\subsubsection{Revisão da farmacoterapia}

Em conformidade com o Conselho Federal de Farmácia (CFF), poderiam ocorrer entre 1,2 a 3,2 milhões de internações por problemas unidos a remédios, sendo que 70\% dos acontecimentos são percebidos como evitáveis.

A revisão da medicação torna-se hábil a desviar-se de que as internações ocorram, criando-se a adesão aos remédios como medidas de precaução. Nas farmácias, é a atividade mais dada, se fazendo em um tipo característico de checkup dos remédios (Matias \& Miranda, 2018).

Presume-se, salvo melhor juízo, que os profissionais de farmácia clamam ao doente pela sua melhora, nesse caso, mesmo que se importe os remédios à farmácia e o faz, trazendo de outros países pela averiguação de sua qualidade, ainda fazem uma revisão detalhada de como tal agente irá se colocar diante do tratamento (Correr \& Otuki, 2013).

Tira indagações, decide problemas, dá orientação o enfermo e desenvolve adesões de tratamentos. Simultaneamente, torna-se hábil de fazer recomendações de mudanças ao profissional de medicina e dar encaminhamento o enfermo (Trindade et al., 2019).

O excelente produto deste serviço da farmácia clínica costuma ser uma listagem necessita dos remédios que o enfermo deve percorrer utilizando. Esta revisão decide problemas da terapêutica e previne averiguações e hospitalizações não previstas.

\subsubsection{Acompanhamento farmacoterapêutico}

A acompanhamento farmacoterapêutico é uma prática farmacêutica que tem como objetivo, prevenir e identificar problemas relacionados a medicamentos (PRM), visando garantir o cuidado do paciente de forma documentada e sistematizada (Campos et al. 2018).

É sabido que os PRMs compõem a principal causa de eventos adversos, que provem de erros de prescrição e na administração de medicamentos, que prejudicam o tratamento do paciente e consequentemente aumentam o período de internação, morbidade, mortalidade e aumento de custos para o hospital (Rosa et al. 2020; Maioli \& Santos, 2018). 
O apoio iniciou-se por meio de uma averiguação de revisão clínica da farmacoterapia, com um enxergar mais voltado aos resultados do tratamento. Adiante, o profissional de farmácia trabalha com o enfermo num plano de cuidado e estrutura averiguações de reaparecimento (Oliveira et al., 2019).

Distante dos serviços precedentes, o amparo farmacoterapêutico possibilita um relacionamento com maior longo e longitudinal com relação ao doente e o profissional de farmácia (Rocha \& Giotto, 2020).

\subsubsection{Gestão da condição de saúde}

Igualmente é chamado de administração da enfermidade. Neste serviço, o profissional comumente assiste e acompanha o enfermo, mas atento em uma doença específica, como o diabetes, a hipertensão ou a hiperlipidemia (Matias \& Miranda, 2018).

Diferente do apoio farmacoterapêutico no qual a análise é mais mundial e generalista. Os serviços de administração da doença são demasiadamente importantes porque tornam-se hábeis de engrandecer a capacidade do doente em ter cuidados farmacêuticos em sua melhora da condição num prisma a objetividade ao autocuidado alegado e defendido (Fantim \& Rodrigues, 2021).

Vários de tais serviços farmacêuticos são implementados por farmácias e drogarias de todo Brasil, exprimem um diferencial concorrente importante e uma nova bases de receitas para as farmácias (Nascimento et al., 2013).

\section{Conclusão}

Foram entendidos vários conceitos sobre intervenção farmacêutica preponderando na sua importância, percebe-se a sua inteira visão sob os aspectos práticos e teórico-conceituais nos quais se versam questionamentos que fizeram acrescentar nos conhecimentos sobre esse desfecho. Ademais, foram observadas as características de ocorrência habituais, que o destacam são peculiares ao contexto da realidade estudada.

No que concerne ao atendimento dos objetivos, considera-se bom o entendimento dos conceitos e ao mesmo tempo, das categorias estudadas com relação ao referido estudo, e nessa apropriação teórico, acabamos percebendo como as vias informativas da amostra dessa pesquisa resultaram em uma excelente conclusão.

Conclui-se que, quanto ao problema que norteou o estudo sobre a intervenção farmacêutica, considera-se atendido, uma vez que ele se destaca em virtude dos fatos e se aponta como destaque em nossa visão teórica da realidade.

Portanto, considera-se viável que esse estudo indica informações precisa a respeito do fenômeno estudado e espera-se que novas discussões possam incrementar ainda mais a ricas informações por este estudo colocadas.

\section{Referências}

Azize, R. L. (2017). Contracepções diversas: uma leitura crítica do dossiê "Contracepção de emergência no Brasil: desafios para a assistência farmacêutica". Saúde e Sociedade, 26, 1136-1142.

Campos. S. T. P. et al. (2018). Acompanhamento farmacoterapêutico e sua importância na prevenção de problemas relacionados ao medicamento (prm) em pacientes hospitalizados. ProgPGP, 5, 1.

Corrêa, A. D. \& Leite, S. Q. M. (2008). Ensino da homeopatia na graduação em farmácia: concepções e práticas pedagógicas em instituições do estado do Rio de Janeiro. Interface-Comunicação, Saúde, Educação, 12, 267-280.

Correr, C. J. \& Otuki, M. F. (2013). A prática farmacêutica na farmácia comunitária. Artmed Editora, A farmácia comunitária (pp. 3-26). Brasil.

Fantim, L. L. M. \& Rodrigues, R. L. (2021). Avaliação das boas práticas de manipulação em farmácias de mogi guaçu e mogi mirim-sp. Foco: caderno de estudos e pesquisas, (16), 30-48.

Farina, S. S. \& Romano, N. S. (2009). Atenção farmacêutica em farmácias e drogarias: existe um processo de mudança? Saúde e sociedade, $18,7-18$. 
Godeiro, D. P. O. (2018). A influência da cultura organizacional na adoção de práticas de qualidade Seis Sigma: um estudo exploratório no segmento de farmácia de manipulação do Estado do Rio Grand do Norte. Dissertação de Mestrado. Universidade Federal do Rio Grande do Norte.

Gramosa, M. R. S. et al. (2018). Evolução da hemovigilância no Brasil: novas perspectivas de atuação do farmacêutico. Rev. Saúde Pública Mato Grosso do Sul (Online), 64-74.

Maioli, N. A. \& Santos, H. C. B. (2018). Intervenções farmacêuticas e sua importância na segurança do paciente hospitalizado. Colloquium Vitae, 10(2), 3540.

Marconi, M. A. \& Lakatos, E. M. (2014). Técnicas de pesquisa: planejamento e execução de pesquisas, amostragens e técnicas de pesquisa, elaboração análise e interpretação de dados. (7a ed.), Atlas, p. 277.

Matias, A. S. \& Miranda, T. A. S. (2018). Implantação do serviço de atenção farmacêutica em uma farmácia comunitária: um estudo exploratório na cidade de São José do Belmonte-PE. ID on line Revista de Psicologia, 12(41), 850-858.

Mendonça, L. G. \& Leite, S. Q. M. (2007). Uso de desenho animado como estratégia de ensino de Boas Práticas de Fabricação em Farmácia para educação profissional técnica de nível médio. Anais do VI Encontro Nacional de Pesquisadores em Ensino de Ciências.

Minayo, M. C. S. (2017). Amostragem e saturação em pesquisa qualitativa: consensos e controvérsias. Revista pesquisa qualitativa, 5(7),. 1-12.

Nascimento, A. et al. (2013). Análise de correspondência múltipla na avaliação de serviços de farmácia hospitalar no Brasil. Cadernos de Saúde Pública, 29, 1161-1172.

Naves, J. O. S. et al. (2008). Práticas de atendimento a DST nas farmácias do Distrito Federal, Brasil: um estudo de intervenção. Cadernos de Saúde Pública, $24,577-586$.

Oliveira, V. G. et al. (2019). Proposta de sala para simulação realística de práticas e serviços farmacêuticos. Profar, 1, 47-55.

Ribeiro, V. F. et al. (2015). Realização de intervenções farmacêuticas por meio de uma experiência em farmácia clínica. Revista Brasileira de Farmácia Hospitalar. 6(4), 18-22

Rocha, A. S. \& Giotto, A. C. (2020). A Importância da Assistência Farmacêutica em Home Care. Revista de Iniciação Científica e Extensão, 3, 390-400.

Rosa, A. W. et al. (2020). Classificação das intervenções farmacêuticas realizadas em unidade de terapia intensiva. Brasil Jornal do Desenvolvimento, 6(6), 40165-40176

Santos, C. O. et al. (2019). Reconciliação medicamentosa: Processo de implantação em um complexo hospitalar com a utilização de sistema eletrônico. Saúde Debate, 43(121), 368-377.

Silveira, M. P. T. et al. (2013). Promovendo boas práticas de Farmácia e Enfermagem no uso de medicamentos no âmbito hospitalar. Revista Brasileira de Farmácia Hospitalar e Serviços de Saúde, 4(1).

Trindade, D. A. M. et al. (2019). Núcleo de atenção farmacêutica: vivências e práticas junto à comunidade. Revista Eletrônica de Extensão, 16(33), 133-144. 